\title{
Oral Contraceptive Use May Attenuate Menstrual Cycle-Induced Ventilatory Changes in Endurance Trained Runners
}

\author{
Kathleen A. Packard ${ }^{*}$, , Thomas L. Lenz ${ }^{1}$, Brad Elder $^{2}$, Corey Godfrey ${ }^{3}$, Randy Holcomb ${ }^{3}$ and \\ Ellie Windle ${ }^{2}$ \\ ${ }^{I}$ Creighton University, School of Pharmacy and Health Professions, Omaha, Nebraska, USA \\ ${ }^{2}$ Doane College, Department of Biology, Crete, Nebraska, USA \\ ${ }^{3}$ Nebraska Heart Institute, Department of Research, Lincoln, Nebraska, USA
}

\begin{abstract}
The relationship between two menstrual cycle phases and cardio respiratory fitness in athletes on oral contraceptives and not on oral contraceptives was assessed in a pilot study. Twelve endurance-trained college cross country runners underwent maximal oxygen consumption treadmill testing, during the late follicular/ovulatory phase and late luteal/premenstrual phase of their menstrual cycle. No significant differences were detected in maximal oxygen consumption between the oral contraceptive group and non-oral contraceptive group or between the two phases. There was a non-significant phase effect in the non-oral contraceptive group with maximal ventilation averaging $90.5 \pm 14.6$ $\mathrm{L} / \mathrm{min}$ during the late follicular/ovulatory phase and decreasing to $79.1 \pm 9.8 \mathrm{~L} / \mathrm{min}$ during the late luteal/premenstrual phase $(\mathrm{p}=0.102)$. Maximal ventilation was significantly lower by $15.6 \%$ between oral contraceptive and non-oral contraceptive users during the late luteal/premenstrual phase $(93.7+7.2 \mathrm{~L} / \mathrm{min} v s 79.1+9.8 \mathrm{~L} / \mathrm{min}, \mathrm{p}=0.014$, respectively). There was no significant phase effect in the oral contraceptive group for maximal ventilation. While oral contraceptive use was associated with an attenuation of the negative effect of the late luteal/premenstrual phase on ventilator performance, there was no effect on maximal oxygen consumption.
\end{abstract}

Keywords: Athlete, women, oral contraceptive, runners, exercise.

\section{INTRODUCTION}

There is a scarcity of literature describing the effects of the menstrual cycle and use of oral contraceptives on the endurance performance of trained female athletes. Oral contraceptive pills remain the leading form of contraception in the US used by 11.6 million women in 2002 [1]. The prevalence of oral contraceptive use in female athletes has continually increased and is now thought to mirror use in non-athletes [2]. Some reports have shown as many as $83 \%$ of elite level athletes use oral contraceptives (98\% monophasic and $2 \%$ triphasic) [3]. A female athlete not taking oral contraceptives will experience monthly changes in hormone levels depending on the phase of the menstrual cycle. This cycle and corresponding fluctuating levels of hormones can affect female athletes in a number of ways. It is well-known that premenstrual and menstrual symptoms such as dysmenorrhea, fatigue, fluid retention, weight gain, and mood changes have the potential to negatively affect performance [4]. There are also more subtle effects of these hormones, both endogenous and exogenous, that may affect physiologic processes in the human body affecting athletic performance. For instance, estrogen has been shown to increase lipid availability and utilization, decrease gluconeogenesis and glycogenolysis, and may even increase plasma volume and cardiac output [5-7]. As endogenous

*Address correspondence to this author at the Creighton University, 2500 California Plaza, Omaha, Nebraska 68178, USA; Tel: 402-481-3915;

Fax: 402-280-1268; E-mail: kpackard@creighton.edu progesterone increases during the menstrual cycle, it can block the action of aldosterone resulting in a loss of sodium and water [7]. Negative feedback activates the renin/angiotensin system to increase aldosterone secretion ultimately leading to fluid retention. Exogenous progesterone administration has also been associated with increased core body temperature [8]. Data also suggest that during the luteal phase (days 16-23), when estradiol and progesterone levels are elevated, lactate production is decreased in response to exercise [9]. Exogenous administration of progesterone has been linked to increases in ventilation and administration of combined oral contraceptives can decrease fasting blood glucose levels and increase serum triglycerides [10-12]. Oral contraceptives can also alter the secretion of insulin and growth hormone [13].

Most survey data in the literature supports a perceived negative effect of the menstrual cycle and use on athletic performance which may be attenuated by the use of oral contraceptives $[7,14,15]$. One survey study in female college physical education students indicated that up to $83.5 \%$ of women reported negative symptoms during the premenstrual and menstrual phase including stomach ache, depression, abdominal cramps, and backache [14]. While only $62 \%$ of those students taking oral contraceptives felt that this affected their physical performance, $77 \%$ of those students not taking oral contraceptives reported the same effect. Likewise, Moller-Nielsen and Hammar demonstrated in a prospective study of 86 soccer players that traumatic injuries were more likely to occur during the premenstrual and menstrual phases as compared to other phases and those 
participants taking oral contraceptives had significantly decreased rates of traumatic injuries [15].

Results of earlier prospective studies assessing the role of menstrual phase and athletic performance are subject to scrutiny due to varying definitions of menstrual phases, lack of hormonal verification using blood assays, and variability in fitness levels [8]. While many studies did not demonstrate an interaction between menstrual phase and performance, those that did were inconsistent with regard to phase effect. Thus, there is no conclusive evidence to support a clear-cut phase effect on exercise performance at this time [4].

Studies assessing the effects of oral contraceptive use on cardio respiratory fitness in athletes are also scarce and conflicting. In an early study, Huisveld et al., did not report any significant differences in cardio respiratory fitness as measured using maximal oxygen consumption or respiratory quotient max assessed via bicycle ergometetry testing on ten trained cyclists, both oral contraceptive users and non-users [16]. Additionally, a study of 12 active women using submaximal treadmill testing to estimate maximal oxygen consumption demonstrated a significant decrease after randomizing women to six months of monophasic oral contraceptives compared to increases in those randomized to barrier contraception [17]. The group also found that nonoral contraceptive users increased their oxygen pulse values by $9 \%$ while oral contraceptive users decreased by $8 \%$ $(\mathrm{p}<0.02)$.

In the first randomized, double-blind, placebo-controlled study, Lebrun et al., assessed the effects of a triphasic oral contraceptive in 14 elite athletes [18]. Participants underwent a baseline cardio respiratory fitness assessment via maximal treadmill testing to measure maximal oxygen consumption during the follicular and luteal phases and were subsequently randomized to either oral contraceptives or placebo for two months. The group randomized to oral contraceptives experienced a decrease in maximal oxygen consumption $(4.7 \%)$ while the placebo group's maximal oxygen consumption increased by $1.5 \%(\mathrm{p} \leq 0.05)$, demonstrating a possible training effect in the placebo group. Interestingly, the investigators found no changes in endurance performance, heart rate, or ventilation to account for this effect. Casazza et al., reported similar findings in a small study in six "moderately active" women [19]. Participants were studied before and after four months of a triphasic oral contraceptive during the follicular and luteal phases. They found no phase effect but did report a decrease in maximal oxygen consumption by $11 \%(\mathrm{p} \leq 0.05)$ after initiation of oral contraceptives, and this decrease was not accompanied by significant changes in ventilation.

Bryner et al., also measured maximal cardio respiratory fitness with treadmill testing in ten athletic women during the follicular and luteal phases in a randomized study [20]. Seven women were randomly assigned to monophasic oral contraceptives and three women were assigned to placebo. There were no significant differences in maximal oxygen consumption or breathing frequency results between different phases or between oral contraceptive and non-oral contraceptive users. Lynch and Nimmo assessed intermittent exercise performance on a treadmill test in five "recreationally active" women on low dose oral contraceptives and ten women not on oral contraceptives [21]. The investigators found no differences in exercise performance between oral contraceptive and non-oral contraceptive users nor was there a phase effect.

In perhaps the largest and most recent study, Rebelo et al., assessed the effects of oral contraceptives on cardio respiratory fitness [22]. Of the 43 active women enrolled, 20 were taking oral contraceptives and 23 were not. The investigators reported no significant differences in maximal oxygen consumption or maximal ventilation when subjected to continuous testing on a cycle ergometer.

Whether or not oral contraceptives can affect cardio respiratory fitness in endurance-trained athletes is still unclear, though it seems that the aerobic effects of oral contraceptives are more pronounced in triphasic formulations as opposed to monophasic formulations [8]. Due to the unclear role of oral contraceptives on the cardio respiratory fitness in this population, this pilot study sought to determine the relationship between two distinct phases of the menstrual cycle and cardio respiratory fitness as measured by a maximal treadmill test (maximal oxygen consumption) in endurance-trained female athletes who were taking oral contraceptives (monophasic and triphasic) and not taking oral contraceptives. Investigators included women already taking both monophasic and triphasic formulations in order to test the effects in a sample representing actual use of oral contraceptives. It was hypothesized that women taking oral contraceptives would have greater maximal oxygen consumption when compared to non-users due to blunted menstrual phase effects.

\section{MATERIALS AND METHODOLOGY}

This study was approved by the Doane College Institutional Review Board and written informed consent was obtained from all participants. Fifteen endurance-trained female collegiate cross country runners were recruited to participate from Doane College in Crete, Nebraska and Nebraska Wesleyan University in Lincoln, Nebraska between November and December 2006. Nine were on oral contraceptives while the other six were on no form of hormone-based birth control. Participants were between 19 to 25 years of age and actively competed in the fall 2006 season of collegiate level cross country without injury. They had a normal menstrual cycle as defined by menstrual period occurring every 25-31 days and for those in the oral contraceptive cohort, they were taking their oral contraception for at least 30 days prior to enrollment. Participants were excluded if they were pregnant, or nursing or planning on becoming pregnant during the course of the study; unwilling to abstain from alcohol, caffeine, weight loss drug/aids, herbal supplements, performance enhancing supplements, or other ergogenic aids for the duration of the study; had a history of any overt congenital or atherosclerotic cardiac disease; or had any acute or chronic condition that could potentially affect athletic performance or put the participant at risk during the study.

After screening and informed consent, three participants were withdrawn from the study - two were lost to follow-up and one had elevated estradiol (E2) levels suggesting noncompliance with oral contraceptives, leaving 12 participants for analysis ( 7 oral contraceptive users and 5 non-users). Participants returned for study visits during two distinct 
phases of their menstrual cycle days 10-14 late follicular/ovulatory (when estrogen levels are rising toward the ovulatory peak) and days 24-28 late luteal/premenstrual (when estrogen and progesterone are declining) in random order, typically whichever occurred first. Participants were instructed to fast for four hours prior to their visits and to abstain from weight loss aids, herbal supplements, alcohol, performance enhancing supplements, or other ergogenic aids throughout the duration of the study. Participants were also instructed to abstain from caffeine intake for 24 hours prior to each study visit. Study visits occurred in the late afternoons to avoid inconsistency with regard to circadian changes.

At the first visit, participants underwent a brief medical history and physical exam including blood pressure, pulse, height, weight, respiratory auscultation lung exam by a physician if a self-reported asthmatic, urine qualitative human chorionic gonadotropin (HCG) pregnancy test, serum estradiol E2 level, body fat sum of skinfolds using calipers, and a cardiologist-interpreted 12 lead electrocardiogram (ECG).

Participants then underwent cardio respiratory exercise testing on a treadmill utilizing the Bruce Protocol administered by the American College of Sports Medicine (ACSM)-certified Exercise Specialists. The metabolic cart utilized for data collection throughout the trial was a Medical Graphics CPX-D system (St. Paul, Minnesota) with mouthpiece and nose clips using the latest version of BreezeSuite $^{\mathrm{TM}}$ software (Medical Graphics, St. Paul, Minnesota) for all data collection. Calibration of the metabolic cart was completed prior to all tests throughout the study. The treadmill used for exercise and ECG monitoring was a Quinton Q-Stress TM55 which was calibrated prior to data collection for the trial.

Participants were screened for contraindications to cardio respiratory exercise testing and were instructed to wear typical running attire and footwear. Participants were instructed on the test procedures including the rating of perceived exertion scale. While supine, participants were prepped for 12 lead ECG monitoring and had resting heart rate, rating of perceived exertion, and blood pressure collected. Two minutes of resting metabolic data were also collected while participants were standing. Participants were then exercised on the treadmill to volitional exhaustion while 12 lead ECG (heart rate), rating of perceived exertion, and expired gases were collected. Metabolic data were collected in a breath by breath fashion. Three minutes of active recovery data were also collected at a speed dictated by the participant and at zero percent grade.

The following data were collected from the cardio respiratory exercise test: total exercise time (minutes:seconds), maximum speed ( $\mathrm{mph}$ ), maximum grade (\%), absolute maximal oxygen consumption (L/min), relative maximal oxygen consumption $(\mathrm{ml} / \mathrm{kg} / \mathrm{min})$, respiratory exchange ratio, maximal ventilation $(\mathrm{L} / \mathrm{min})$, maximum heart rate (bpm), absolute (maximal volume of carbon dioxide) maximal carbon dioxide production $(\mathrm{L} / \mathrm{min})$, and maximum rating of perceived exertion. Participants then returned to the clinic for their second visit during the second phase of their menstrual cycle and underwent repeat cardio respiratory exercise testing.
This was a per protocol analysis. Statistical analysis was completed utilizing SAS $^{\circledR}$ version 9.1 statistical software (SAS Institute Inc. Cary, North Carolina). Differences in baseline background characteristics between participants taking oral contraceptives and not taking oral contraceptives were compared using the Chi Square test for categorical variables and independent $\mathrm{t}$ tests for continuous variables. Differences between weight, resting heart rate, maximal oxygen consumption, maximal ventilation, and time to exhaustion were compared between the late follicular/ovulatory phase and late luteal/premenstrual phase in both oral contraceptive users and non-users using match paired $\mathrm{t}$ tests. $\mathrm{P}$ values less than 0.05 were considered statistically significant.

\section{RESULTS}

Table 1 describes the physical characteristics of the study participants. Women in the oral contraceptive group were significantly older $(21.0 \pm 0.82$ years vs $19.6 \pm 0.89$ years, $\mathrm{p}<0.05)$ and taller $(67.3 \pm 3.20$ inches vs $63.2 \pm 1.92$ inches, $\mathrm{p}<0.05)$ than those not taking oral contraceptives.

Table 1. Summary of Physical Characteristics of Study Participants

\begin{tabular}{|c|c|c|}
\hline & $\begin{array}{c}\text { Participants } \\
\text { on OC } \\
n=7\end{array}$ & $\begin{array}{c}\text { Participants } \\
\text { Not on OC } \\
n=5\end{array}$ \\
\hline $\operatorname{Age}($ years $\pm S D) *$ & $21.0 \pm 0.82$ & $19.6 \pm 0.89$ \\
\hline Asthmatic n (\%) & $1(14.3)$ & $1(20)$ \\
\hline Height (inches \pm SD)* & $67.3 \pm 3.20$ & $63.2 \pm 1.92$ \\
\hline Body Fat Sum of Skinfolds $(\mathrm{mm} \pm$ SD) & $44.86+8.55$ & $51.2+11.1$ \\
\hline Estrogen Level $(\mathrm{pg} / \mathrm{ml} \pm \mathrm{SD}) *$ & $<20$ & $125.6+76.1$ \\
\hline $\mathrm{SBP}$ at $\mathrm{LFO}(\mathrm{mmHg} \pm \mathrm{SD})$ & $104.3 \pm 13.19$ & $110.0 \pm 6.63$ \\
\hline DBP at $\mathrm{LFO}(\mathrm{mmHg} \pm \mathrm{SD})$ & $61.4 \pm 6.70$ & $63.6 \pm 8.29$ \\
\hline SBP at LLP $(\mathrm{mmHg} \pm \mathrm{SD})$ & $100.3 \pm 11.10$ & $99.6 \pm 6.84$ \\
\hline DBP at LLP $(\mathrm{mmHg} \pm \mathrm{SD})$ & $58.0 \pm 7.48$ & $60.0 \pm 4.90$ \\
\hline
\end{tabular}

*Statistically significant at the level $\mathrm{p}<0.05$.

OC- oral contraceptive, SBP - systolic blood pressure, DBP - diastolic blood pressure, LFO - late follicular/ovulatory, LLP- late luteul/premenstrual.

Table 2 summarizes the components in the oral contraceptives. All women were taking between 25 and 35 mcg of ethinyl estradiol. Three women were taking triphasic formulations and four were taking monophasic formulations.

There was no significant training effect for any of the exercise variables tested in athletes between the two visits (maximal oxygen consumption, maximal ventilation, or time to exhaustion). No significant differences were detected in maximal oxygen consumption between the late follicular/ovulatory phase and the late luteal/premenstrual phase (Tables 3 and 4) nor between the oral contraceptive group and non-oral contraceptive group (Tables 5 and 6 ).

There was a non-significant phase effect in the non-oral contraceptive group $(\mathrm{p}=0.102)$ with maximal ventilation averaging $90.5 \pm 14.6 \mathrm{~L} / \mathrm{min}$ during the late follicular/ovulatory phase and decreasing to an average of $79.1 \pm 9.8 \mathrm{~L} / \mathrm{min}$ during 
Table 2. Summary of Oral Contraceptive Components in Participants

\begin{tabular}{|c|c|c|c|}
\hline $\begin{array}{l}\text { Subject } \\
\text { Number }\end{array}$ & Brand Name Oral Contraceptive & Phase & Generic Component \\
\hline 1 & $\begin{array}{l}\text { Ortho Cyclen }^{\circledR} \text { (Ortho-McNeil-Janssen } \\
\text { Pharmaceuticals, Titusville, New Jersey) }\end{array}$ & Monophasic & Ethinyl estradiol $35 \mathrm{mcg}$ and norgestimate $0.25 \mathrm{mg}$ \\
\hline 2 & $\begin{array}{c}\text { Zovia }^{\circledR} \text { (Watson Pharmaceuticals, Corona, } \\
\text { California) }\end{array}$ & Monophasic & Ethinyl estradiol $35 \mathrm{mcg}$ and ethynodiol diacetate $1 \mathrm{mg}$ \\
\hline 4 & $\begin{array}{l}\text { Ortho Tri Cyclen Lo }{ }^{\circledR} \text { (Ortho-McNeil-Janssen } \\
\text { Pharmaceuticals, Titusville, New Jersey) }\end{array}$ & Triphasic & $\begin{array}{l}\text { Day 1-7: Ethinyl estradiol } 25 \mathrm{mcg} \text { and norgestimate } 0.18 \mathrm{mg} \\
\text { Day 8-14: Ethinyl estradiol } 25 \mathrm{mcg} \text { and norgestimate } 0.215 \mathrm{mg} \\
\text { Day 15-21: Ethinyl estradiol } 25 \mathrm{mcg} \text { and norgestimate } 0.25 \mathrm{mg} \\
\text { Day 22-28: inactive tablets }\end{array}$ \\
\hline 5 & $\begin{array}{l}\text { Nortrel }^{\mathrm{TM}} \text { (generic for Ortho Novum } \\
\text { McNeil-Janssen Pharmaceuticals, Titusville, New } \\
\text { Jersey) }\end{array}$ & Monophasic & Ethinyl estradiol $35 \mathrm{mcg}$ and norethindrone $1 \mathrm{mg}$ \\
\hline 7 & $\begin{array}{l}\text { Tri Sprintec }{ }^{\circledR} \text { Ortho (generic for Tri Cyclen }{ }^{\circledR}, \text { Ortho- } \\
\text { McNeil-Janssen Pharmaceuticals, Titusville, New } \\
\text { Jersey) }\end{array}$ & Triphasic & $\begin{array}{l}\text { Day 1-7: Ethinyl estradiol } 35 \mathrm{mcg} \text { and norgestimate } 0.18 \mathrm{mg} \\
\text { Day 8-14: Ethinyl estradiol } 35 \mathrm{mcg} \text { and norgestimate } 0.215 \mathrm{mg} \\
\text { Day 15-21: Ethinyl estradiol } 35 \mathrm{mcg} \text { and norgestimate } 0.25 \mathrm{mg} \\
\text { Day 22-28: inactive tablets }\end{array}$ \\
\hline 9 & $\begin{array}{c}\text { Seasonale }^{\circledR} \text { (Teva Pharmaceutical Industries, North } \\
\text { Wales, Pennsylvania) }\end{array}$ & Monophasic & Ethinyl estradiol $30 \mathrm{mcg}$ and levonorgestrel $0.15 \mathrm{mg}$ \\
\hline 11 & $\begin{array}{l}\text { Ortho Tri Cyclen Lo }{ }^{\circledR} \text { (Ortho-McNeil-Janssen } \\
\text { Pharmaceuticals, Titusville, New Jersey) }\end{array}$ & Triphasic & $\begin{array}{c}\text { Day 1-7: Ethinyl estradiol } 25 \mathrm{mcg} \text { and norgestimate } 0.18 \mathrm{mg} \\
\text { Day 8-14: Ethinyl estradiol } 25 \mathrm{mcg} \text { and norgestimate } 0.215 \mathrm{mg} \\
\text { Day 15-21: Ethinyl estradiol } 25 \mathrm{mcg} \text { and norgestimate } 0.25 \mathrm{mg} \\
\text { Day 22-28: inactive tablets }\end{array}$ \\
\hline
\end{tabular}

Table 3. Oral Contraceptive Users Late Follicular/Ovulatory Phase vs Late Luteal/Premenstrual Phase

\begin{tabular}{|c|c|c|c|}
\hline & $\begin{array}{c}\text { Late Follicular/Ovulatory Phase } \\
\text { Days 10-14 } \\
\text { n=7 }\end{array}$ & $\begin{array}{c}\text { Late Luteal/Premenstrual Phase } \\
\text { Days 24-28 } \\
\mathbf{n}=7\end{array}$ & $\begin{array}{c}\text { Paired T-Test } \\
\text { p Value }\end{array}$ \\
\hline Weight (Pounds \pm SD) & $125.3 \pm 7.5$ & $125.1 \pm 10.2$ & 0.941 \\
\hline Resting Heart Rate $(\mathrm{bpm} \pm$ SD) & $57.2 \pm 10.4$ & $59.7 \pm 10.2$ & 0.647 \\
\hline $\mathrm{VO}_{2 \max }(\mathrm{ml} / \mathrm{kg} / \mathrm{min} \pm \mathrm{SD})$ & $53.9 \pm 3.2$ & $53.0 \pm 3.0$ & 0.671 \\
\hline
\end{tabular}

bpm - beats per minute, $\mathrm{VO}_{2} \max$ - maximal oxygen consumption, $\mathrm{VE}_{\max }$ - maximal ventilation.

Table 4. Non-Oral Contraceptive Users Late Follicular/Ovulatory Phase vs Late Luteal/Premenstrual Phase

\begin{tabular}{|c|c|c|c|}
\hline & $\begin{array}{c}\text { Late Follicular/Ovulatory Phase Days 10-14 } \\
\mathbf{n}=\mathbf{5}\end{array}$ & $\begin{array}{c}\text { Late Luteal/Premenstrual Phase Days 24-28 } \\
\mathbf{n}=\mathbf{5}\end{array}$ & $\begin{array}{c}\text { Paired T-Test } \\
\mathbf{p ~ V a l u e}\end{array}$ \\
\hline \hline Weight (Pounds $\pm \mathbf{S D})$ & $122.2 \pm 7.3$ & $122.8 \pm 7.0$ & 0.070 \\
\hline Resting Heart Rate $(\mathbf{b p m} \pm \mathbf{S D})$ & $58.0 \pm 6.2$ & $57.6 \pm 12.2$ & 0.957 \\
\hline $\mathbf{V O}_{\text {max }}(\mathbf{m l} / \mathbf{k g} / \mathbf{m i n} \pm \mathbf{S D})$ & $54.2 \pm 5.5$ & $52.2 \pm 4.1$ & 0.391 \\
\hline $\mathbf{V E}_{\mathbf{m a x}}(\mathbf{L} / \mathbf{m i n} \pm \mathbf{S D})$ & $90.5 \pm 14.6$ & $79.1 \pm 9.8$ & 0.102 \\
\hline Time to Exhaustion $(\mathbf{m i n} \pm \mathbf{S D})$ & $15: 51 \pm 3: 56$ & $15: 14 \pm 3: 23$ & 0.468 \\
\hline
\end{tabular}

bpm - beats per minute, $\mathrm{VO}_{2 \max }-$ maximal oxygen consumption, $\mathrm{VE}_{\max }-$ maximal ventilation.

the late luteal/premenstrual phase. Maximal ventilation was significantly lower by $15.6 \%$ between oral contraceptive and non-oral contraceptive users during the late luteal/premen- strual phase $(93.7 \pm 7.2 \mathrm{~L} / \mathrm{min}$ vs $79.1 \pm 9.8 \mathrm{~L} / \mathrm{min}, \mathrm{p}=0.014)$. There was no significant cycle effect in the oral contraceptive group for maximal ventilation. 
Table 5. Late follicular/Ovulatory Phase Oral Contraceptive Users vs Non-Oral Contraceptive Users

\begin{tabular}{|c|c|c|c|}
\hline & OC Users $\mathbf{n}=\mathbf{7}$ & Non-OC Users $\mathbf{n}=\mathbf{5}$ & Student's T-Test $\mathbf{p}$ Value \\
\hline \hline Weight $($ Pounds $\pm \mathbf{S D})$ & $125.3 \pm 7.5$ & $122.2 \pm 7.3$ & 0.494 \\
\hline Resting Heart Rate $(\mathbf{b p m} \pm \mathbf{S D})$ & $59.3 \pm 11.0$ & $58.0 \pm 6.2$ & 0.819 \\
\hline $\mathbf{V} \mathbf{O}_{\mathbf{m a x}}(\mathbf{m l} / \mathbf{k g} / \mathbf{m i n} \pm \mathbf{S D})$ & $53.9 \pm 3.2$ & $54.2 \pm 5.5$ & 0.892 \\
\hline $\mathbf{V E}_{\max }(\mathbf{L} / \mathbf{m i n} \pm \mathbf{S D})$ & $90.2 \pm 7.7$ & $90.5 \pm 14.6$ & 0.961 \\
\hline Time to Exhaustion $(\mathbf{m i n} \pm \mathbf{S D})$ & $14: 10 \pm 1: 17$ & $15: 51 \pm 3: 56$ & 0.401 \\
\hline
\end{tabular}

$\mathrm{OC}$ - oral contraceptive, bpm - beats per minute, $\mathrm{VO}_{2 \max }-$ maximal oxygen consumption, $\mathrm{VE}_{\max }-$ maximal ventilation.

Table 6. Late Luteal/Premenstrual Phase Oral Contraceptive Users vs Non-Oral Contraceptive Users

\begin{tabular}{|c|c|c|c|}
\hline & OC Users $\mathbf{n}=\mathbf{7}$ & Non-OC Users $\mathbf{n}=\mathbf{5}$ & Student's T-Test $\mathbf{p}$ Value \\
\hline \hline Weight $($ Pounds \pm SD) & $125.1 \pm 10.2$ & $122.8 \pm 7.0$ & 0.668 \\
\hline Resting Heart Rate $(\mathbf{b p m} \pm \mathbf{S D})$ & $59.7 \pm 10.2$ & $57.6 \pm 12.2$ & 0.766 \\
\hline $\mathbf{V O}_{2 \max }(\mathbf{m l} / \mathbf{k g} / \mathbf{m i n} \pm \mathbf{S D})$ & $53.0 \pm 3.0$ & $52.2 \pm 4.1$ & 0.734 \\
\hline $\mathbf{V E}_{\max }(\mathbf{L} / \mathbf{m i n} \pm \mathbf{S D})$ & $93.7 \pm 7.2$ & $79.1 \pm 9.8$ & $\mathbf{0 . 0 1 4}$ \\
\hline Time to Exhaustion $(\mathbf{m i n} \pm \mathbf{S D})$ & $13: 24 \pm 0: 39$ & $15: 14 \pm 3: 23$ & 0.297 \\
\hline
\end{tabular}

$\mathrm{OC}$ - oral contraceptive, bpm - beats per minute, $\mathrm{VO}_{2 \max }-$ maximal oxygen consumption, $\mathrm{VE}_{\max }-$ maximal ventilation.

\section{DISCUSSION}

The non-significant late luteal/premenstrual phase decline in maximal ventilation observed in non-oral contraceptive users compared to oral contraceptive users in this study may be explained by the decline in progesterone levels known to occur during this phase, which are likely more pronounced in non-oral contraceptive users. It has been previously shown that there is a reduction in levels of alveolar pulmonary carbon dioxide elimination and increases in ventilatory drives and exercise ventilation during the luteal phase of the menstrual cycle, possibly due to elevated levels of progesterone [23-25]. It is thought that this is modulated through an increased chemosensitivity to hypoxia and hypercapnia [23]. Both athletes and non-athletes show increases in resting ventilation and mouth occlusion pressure during the luteal phase vs the follicular phase [25]. As progesterone levels decline, it would be expected to see a reduction in ventilator response. This decline in progesterone, also a smooth muscle relaxant, could also lead to broncho constriction through withdrawal on bronchial smooth muscle [4].

While some studies did not report differences in ventilator changes between oral contraceptive and non-oral contraceptive users $[18,19,22]$, others are consistent with these findings. An early, small study in 12 non-athletic women found that the addition of oral contraceptives led to non-significant increases in ventilator performance during moderate treadmill exercise when compared to non-oral contraceptive use [24]. Similar to our results, Schoene et al., found that this change in ventilation during the luteal phase occurred in both athletes and non-athletes [25]. Like our results, this change did not affect the cardio respiratory fitness of endurance-trained athletes nor did it correlate to levels of progesterone. This lack of correlation may be due to a time-phase delay, circulating levels of bound progesterone, or interaction with estradiol [4]. A more recent study in 13 female cyclists/triathletes on a monophasic oral contraceptive (ethinyl estradiol 30-35 mcg and various forms of progesterone) demonstrated no significant differences in power output or maximal oxygen consumption between the late luteal/premenstrual phase, the premenstrual/menstrual phase, and the ovulatory phase during bicycle endurance testing [26]. The investigators did however, report a significantly higher maximal ventilation during the ovulatory phase as compared to the late luteal/premenstrual and premenstrual phases when progesterone would be declining (68.9 $\mathrm{L} / \mathrm{min}$ vs $65.5 \mathrm{~L} / \mathrm{min}$ and $63.3 \mathrm{~L} / \mathrm{min}$, respectively, $\mathrm{p}<0.05)$.

Studying the effects of the menstrual cycle and oral contraceptive use is complex and involves variability not only between participants and but also within cycles of the individual participants. Time of testing, level of athleticism, dose of hormones in the oral contraceptives, and whether or not monophasic or triphasic formulations are used can all potentially affect results. The primary limitations of this study are the small number of participants enrolled and the fact that participants were taking various forms of oral contraceptives. However, the variety of formulations used in this study may represent actual use in the female athlete population. The fact that the non-oral contraceptive group of women were younger, shorter in height, and possibly less experienced with collegiate athletics than the oral contraceptive group could have also affected the results. Because this study did not include an inclusion/exclusion criterion for level of fitness or cardio respiratory capacity, differences in results may have been related to individual variability rather than the use of oral contraceptives or phase. However, because participants were enrolled from collegiate cross country teams, differences in cardio respiratory fitness were limited as much as possible. 
Table 7. Exercise Testing Data in Asthmatic Participants

\begin{tabular}{|c|c|c|c|c|c|}
\hline Subject \# & OC Use & $\mathrm{LFO} \mathrm{VO}_{2 \max }(\mathrm{ml} / \mathbf{k g} / \mathrm{min})$ & $\mathbf{L F O ~ V E}_{\max }(\mathrm{L} / \mathrm{min})$ & $\operatorname{LLP~VO}_{2 \max }(\mathrm{ml} / \mathrm{kg} / \mathrm{min})$ & $\operatorname{LLP}_{\mathbf{V}} \mathbf{E}_{\max }(\mathbf{L} / \mathrm{min})$ \\
\hline 2 & Yes & 51.5 & 93.1 & 55 & 95.6 \\
\hline 10 & No & 63.8 & 109.8 & 55.3 & 91.6 \\
\hline
\end{tabular}

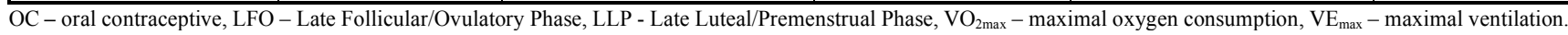

Small differences in performance of endurance-trained athletes can greatly influence their success. Therefore, as more and more female athletes use oral contraceptives, it is important to differentiate between the various formulations, especially with respect to ventilator response. While changes in ventilator response did not seem to affect overall maximal oxygen consumption measurements of the endurance-trained athletes in this study, this finding may be important for nonathletes or those women with respiratory disease such as asthma. Interestingly, there were two women with asthma enrolled in this study, one taking oral contraceptives and one not taking oral contraceptives (Table 7).

Only the asthmatic participant not taking oral contraceptives experienced a reduction in maximal ventilation $(109.8 \mathrm{~L} / \mathrm{min}$ to $91.6 \mathrm{~L} / \mathrm{min})$ and a reduction in maximal oxygen consumption $(63.8 \mathrm{ml} / \mathrm{kg} / \mathrm{min}$ to 55.3 $\mathrm{ml} / \mathrm{kg} / \mathrm{min}$ ) between the late follicular/ovulatory phase and the late luteal/premenstrual phase. Only larger, controlled studies in endurance-trained athletes with the inclusion of those with asthma will shed light on this finding.

\section{CONCLUSIONS}

This study demonstrated that there may be a menstrual cycle effect in that maximal ventilation is lower in the late luteal/premenstrual phase which is attenuated by the use of oral contraceptives. This suggests that the use of oral contraceptives may allow for more consistent cardio respiratory fitness throughout the menstrual cycle. While maximal oxygen consumption was not changed in this study, larger studies will determine whether or not this would affect overall performance.

Whether or not oral contraceptives can affect cardio respiratory fitness in endurance-trained athletes is still unclear, though it has been suggested that the aerobic effects of oral contraceptives are more pronounced in triphasic formulations as opposed to monophasic formulations [8]. While our study sample included women taking both monophasic and triphasic formulations, it has been suggested that monophasic formulations may provide a controlled environment for the athlete and minimize physiological variation associated with endogenous hormones [8]. Until larger randomized controlled trials are conducted to distinguish the differences between monophasic and triphasic formulations, these results should be interpreted with caution. As hormone levels in formulations continue to decrease over time, it is likely that the other beneficial effects of oral contraceptive such as decreased bleeding and reduced incidence of anemia, preserved bone density, and control of premenstrual and menstrual symptoms will outweigh any slight detriment to cardio respiratory fitness and may possibly blunt cycle-induced ventilator changes in some women.

\section{CONFLICT OF INTEREST}

None of the authors (Kathleen Packard, Thomas Lenz, Brad Elder, Ellie Windle, Randall Holcomb, or Corey Godfrey) have any commercial associations to disclose that would create a conflict of interest in association with the research described in this manuscript.

\section{ACKNOWLEDGEMENTS}

The authors would like to thank Stephen Swanson, MD of The Women's Clinic of Lincoln, Nebraska and Steven Martin, MD from The Nebraska Heart Institute of Lincoln, Nebraska for their assistance with protocol development and data interpretation. They would also like to thank Kay Ryschon, MS for her statistical support. This study was funded through support from Doane College (Crete, Nebraska) and the Nebraska Heart Institute (Lincoln, Nebraska).

\section{REFERENCES}

[1] Mosher WD, Martinez GM, Chandra A, Abma JC, Willson SJ. Use of contraception and use of family planning services in the United States: 1982-2002. Advance Data from Vital and Health Statistics, US Department of Health and Human Services 2004; 350:1-36.

[2] Bennell K, White S, Crossley K. The oral contraceptive pill: a revolution for sportswomen? Br J Sports Med 1999; 33: 231-8.

[3] Rechichi C, Dawson B, Goodman C. Athletic performance and the oral contraceptive. Int J Sports Physiol Perform 2009; 4: 151-62.

[4] Constantini NW, Dubnov G, Lebrun CM. The menstrual cycle and sport performance. Clin Sports Med 2005; 25(2): 51-82.

[5] Bunt JC. Metabolic actions of estradiol: significance for acute and chronic exercise response. Med Sci Sports Exerc 1990; 22(3): 28690.

[6] Fortney SM, Beckett WS, Carpenter AJ, et al. Changes in plasma volume during bedrest: effects of menstrual cycle and estrogen administration. J Appl Physiol 1988; 65(2): 525-33.

[7] Lebrun CM. Effect of the different phases of the menstrual cycle and oral contraceptives on athletic performance. Sports Med 1993; 16(6): 400-30.

[8] Burrows M, Peters CE. The influence of oral contraceptives on athletic performance in female athletes. Sports Med 2007; 37(7): 557-74.

[9] Jurkowski JE, Jones NL, Toews CJ, Sutton JR. Effects of menstrual cycle on blood lactate, $\mathrm{O}_{2}$ delivery, and performance during exercise. J Appl Physiol 1981; 51(6): 1493-9.

[10] Bonekat HW, Dombovy ML, Staats BA. Progesterone-induced changes in exercise performance and ventilator response. Med Sci Sports Exerc 1987; 19(2): 118-23.

[11] Skouby SO, Wagner HH, Andersen O. The short-term effects of a low-dose oral contraceptive on glucose metabolism, plasma lipids and blood clotting factors. Contraception 1983; 28: 489-99.

[12] Tikkanen MJ. Role of plasma lipoproteins in the pathogenesis of atherosclerotic disease, with special reference to sex hormone effects. Am J Obstet Gynecol 1990; 163: 296-304.

[13] Bemben DA. Metabolic effects of oral contraceptives. Sports Med 1993; 16(5): 295-304.

[14] Bale P, Davies J. Effects of menstruation and contraceptive pill on the performance of physical education students. Br J Sports Med 1983; 17: 46-50.

[15] Moller-Nielsen J, Hammar M. Women's soccer injuries in relation to the menstrual cycle and oral contraceptive use. Med Sci Sports Exerc 1989; 21(2): 126-9. 
[16] Huisveld IA, Hospers JE, Bernink MJ, Erich WB, Bouma BN. The effect of oral contraceptives and exercise on hemostatic and fibrinolytic mechanisms in trained women. Int J Sports Med 1983; 4(2): 97-103.

[17] Notelovitz M, Zauner C, McKenzie L, Suggs Y, Fields C, Kitchens C. The effect of low-dose oral contraceptives on cardio respiratory function, coagulation, and lipids in exercising young women: a preliminary report. Am J Obstet Gynecol 1987; 156: 591-8.

[18] Lebrun CM, Petit MA, McKenzie DC, Taunton JE, Prior JC. Decreased maximal aerobic capacity with the use of a triphasic oral contraceptive in highly active women: a randomized controlled trial. Br J Sports Med 2003; 37: 315-20.

[19] Casazza GA, Suh SH, Miller BF, Navazio FM, Brooks GA. Effects of oral contraceptives on peak exercise capacity. J Appl Physiol 2002; 93: 1698-702.

[20] Bryner RW, Toffle RC, Ullrich IH, Yeater RA. Effect of low dose oral contraceptives on exercise performance. Br J Sports Med 1996; 30: 36-40.
[21] Lynch NJ, Nimmo MA. Effects of menstrual cycle phase and oral contraceptive use on intermittent exercise. Eur J Appl Physiol 1998; 78: 565-72.

[22] Rebelo ACS, Zuttin RS, Verlengia R, Cesar MDC, Silva de Sa MF, Silva ED. Effect of low-dose combined oral contraceptive on aerobic capacity and anaerobic threshold level in active and sedentary young women. Contraception 2010; 81: 309-15.

[23] England SJ, Farha LE. Fluctuations in alveolar $\mathrm{CO}_{2}$ and in base excess during the menstrual cycle. Respir Physiol 1976; 26(2): 15761.

[24] Montes A, Lally D, Hale RW. The effects of oral contraceptives on respiration. Fertil Steril 1983; 39(4): 515-9.

[25] Schoene RB, Robertson HT, Pierson DJ, Peterson AP. Respiratory drives and exercise in menstrual cycles of athletic and nonathletic women. J Appl Physiol 1981; 50(6): 1300-5.

[26] Rechichi C, Dawson B, Goodman C. Oral contraceptive phase has no effect on endurance test. Int J Sports Med 2008; 29: 277-81.

(C) Packard et al.; Licensee Bentham Open.

This is an open access article licensed under the terms of the Creative Commons Attribution Non-Commercial License (http://creativecommons.org/licenses/by-nc/3.0/) which permits unrestricted, non-commercial use, distribution and reproduction in any medium, provided the work is properly cited. 